\title{
Nature of the acceptor responsible for $p$-type conduction in liquid encapsulated Czochralski-grown undoped gallium antimonide
}

\author{
C. C. Ling, ${ }^{\text {a) }}$ M. K. Lui, S. K. Ma, X. D. Chen, S. Fung, and C. D. Beling \\ Department of Physics, The University of Hong Kong, Pokfulam Road, Hong Kong, \\ People's Republic of China
}

(Received 29 September 2003; accepted 21 May 2004)

\begin{abstract}
Acceptors in liquid encapsulated Czochralski-grown undoped gallium antimonide (GaSb) were studied by temperature dependent Hall measurement and positron lifetime spectroscopy (PLS). Because of its high concentration and low ionization energy, a level at $E_{V}+34 \mathrm{meV}$ is found to be the important acceptor responsible for the $p$-type conduction of the samples. Two different kinds of $\mathrm{V}_{\mathrm{Ga}}$-related defects (lifetimes of $280 \mathrm{ps}$ and $315 \mathrm{ps}$, respectively) having different microstructures were characterized by PLS. By comparing their annealing behaviors and charge state occupancies, the $E_{V}+34 \mathrm{meV}$ level could not be related to the two $\mathrm{V}_{\mathrm{Ga}}$-related defects. () 2004 American Institute of Physics. [DOI: 10.1063/1.1773934]
\end{abstract}

Gallium antimonide GaSb is a direct band-gap semiconductor suitable for fabricating high-frequency electronic devices and optoelectronic devices operating in the $2-4 \mu \mathrm{m}$ wavelength region. $\mathrm{GaSb}$ is also the suitable substrate for growing various III-V compounds with bandgaps varying over a wide range from $0.3-1.58 \mathrm{eV}$ (i.e., $0.8-4.3 \mu \mathrm{m}){ }^{1,2}$ Undoped $\mathrm{GaSb}$ is usually $p$-type material ( $p$ $\sim 10^{16}-10^{17} \mathrm{~cm}^{-3}$ ) with a residual acceptor that is doubly ionizable and related to $\mathrm{Ga}$ in excess. This acceptor has been usually associated with the $\mathrm{Ga}$ vacancy or the $\mathrm{V}_{\mathrm{Ga}} \mathrm{Ga}_{\mathrm{Sb}}$ complex ${ }_{3,4}^{1,2}$ although some reports have suggested a structure of $\mathrm{Ga}_{\mathrm{Sb}} ., 4$

Positron annihilation spectroscopy is a useful probe for studying vacancy-type defects in semiconductors. ${ }^{5-9}$ In the previous positron lifetime studies, ${ }^{10,11}$ we have observed a $\sim 315$ ps lifetime component in heavily Zn-doped and undoped $p$-type $\mathrm{GaSb}$ materials. This component was attributed to the $\mathrm{V}_{\mathrm{Ga}}$-related defect. This defect annealed at temperatures of $300-400{ }^{\circ} \mathrm{C}$. In contrast, the hole concentrations observed in the undoped samples show no significant change $\left(p \sim 10^{17} \mathrm{~cm}^{-3}\right)$ with annealing temperature up to $500{ }^{\circ} \mathrm{C}$. This implies that, at least for the samples annealed at $T_{a}$ $\geqslant 300{ }^{\circ} \mathrm{C}, \mathrm{V}_{\mathrm{Ga}}$ related defect is not the acceptor responsible for the $p$-type conduction. The present study aims at investigating the identity of the residual acceptor and the role of the $\mathrm{V}_{\mathrm{Ga}}$-related defect in determining the undoped material's hole concentration by performing temperature dependent Hall (TDH) and positron lifetime spectroscopy (PLS) measurements.

Samples of $1 \times 1 \mathrm{~cm}^{2}$ were cut from the liquid encapsulated Czochralski (LEC)-grown undoped $p$-type GaSb wafers. The annealing steps were performed in forming gas $\left(\mathrm{N}_{2}: \mathrm{H}_{2}=80 \%: 20 \%\right)$ for a period of $30 \mathrm{~min}$. The TDH measurements were performed with the Accent HL5500 system. The positron lifetime spectrometer is a conventional fast-fast system having a full width at half maximum resolution of 200 ps or 230 ps. Each of the PLS spectra contained 4 $\times 10^{6}$ events. The positron lifetime spectra were decomposed by the POSITRONFIT code, ${ }^{12}$ which considered the spectrum a) Author to whom correspondence should be addressed; electronic mail:
ccling@hku.hk to be of the form of $S(t)=\Sigma I_{i} \exp \left(-t / \tau_{i}\right)$, where $I_{i}$ and $\tau_{i}$ are the intensity and the characteristic lifetime of the corresponding annihilating states.

TDH measurements $(4 \mathrm{~K}-300 \mathrm{~K})$ were performed on nonirradiated and electron $\left(e^{-}\right)$-irradiated $(1.7 \mathrm{MeV}$ and $10^{17} \mathrm{~cm}^{-2}$ ) undoped samples. From the charge neutrality condition, the hole concentration $p$, the electron concentration $n$, the effective donor concentration $N_{D}$, the concentrations $N_{A i}$, and the ionization energies $E_{A i}$, of the acceptors are given by: $p+N_{D}=n+\Sigma N_{A i}\left\{1+g \exp \left[\left(E_{A i}-E_{F}\right) /(k T)\right]\right\}^{-1}$. This equation was used to fit the TDH data with $n=0$ and $g=4$. Four acceptors A1, A2, A3, and A4 were detected in all of these samples having the following ionization energies and concentrations, $\quad E_{\mathrm{A} 1}=4-10 \mathrm{meV}, \quad C_{\mathrm{A} 1}=2 \times 10^{13}-1$ $\times 10^{15} \mathrm{~cm}^{-3} ; E_{\mathrm{A} 2}=31-35 \mathrm{meV}, C_{\mathrm{A} 2}=0.2-2.3 \times 10^{18} \mathrm{~cm}^{-3}$; $E_{\mathrm{A} 3} \sim 89 \mathrm{meV}, C_{\mathrm{A} 3} \sim 10^{16} \mathrm{~cm}^{-3}$, and $E_{\mathrm{A} 4} \sim 120 \mathrm{meV}, C_{\mathrm{A} 4}$ $\sim 10^{16} \mathrm{~cm}^{-3}$. Because of its low concentration, A1 could not be the dominant acceptor providing the $p$-type conductivity. A3 and A4 are also unlikely candidates due to their large ionization energies and low concentration. The A2 acceptor remains as the most important acceptor. Hole and the A2 concentrations are shown as a function of the annealing temperature in Fig. 1. They remain unchanged in the nonirradiated sample in the range of $1.8-2 \times 10^{17} \mathrm{~cm}^{-3}$. For the irradiated sample, however, the A2 concentration increases sharply to $2.2 \times 10^{18} \mathrm{~cm}^{-3}$ for annealing above $300{ }^{\circ} \mathrm{C}$.

In our previous PLS study on the nonirradiated undoped GaSb materials, ${ }^{11}$ the lifetime spectra were well described by the single defect model ( $\left.\tau_{d} \sim 315 \mathrm{ps}\right)$ for samples annealed at $T_{a} \leqslant 300{ }^{\circ} \mathrm{C}$. For those samples annealed at $T_{a}>300{ }^{\circ} \mathrm{C}$, a single component fit, attributed to the $\mathrm{V}_{\mathrm{Ga}}$-related defect, gave a good description. Here, we report on a PLS study of $\mathrm{e}^{-}$-irradiated undoped GaSb. ${ }^{13}$ The main finding is that a single defect trapping model can represent the spectra of samples annealed at $T_{a}>300{ }^{\circ} \mathrm{C}$, but fails for spectra annealed at $T_{a}<300{ }^{\circ} \mathrm{C}$. The most likely explanation for such an observation is that at $T_{a}<300{ }^{\circ} \mathrm{C}$, the $280 \mathrm{ps}$ and the $315 \mathrm{ps}$ components coexist, whereas for $T_{a}<300{ }^{\circ} \mathrm{C}$, only the 280 ps survives with the 315 ps component annealed out. As the samples maintain their $p$-type conductivity upon annealing, the $280 \mathrm{ps}$ lifetime component is again attributed to 


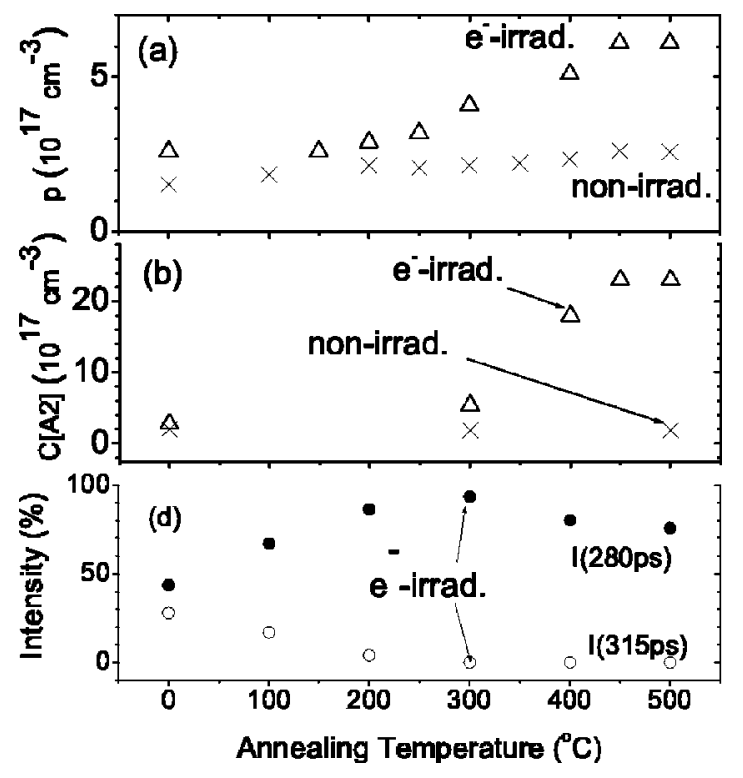

FIG. 1. (a) Hole concentrations of the nonirradiated and e-irradiated undoped GaSb samples as a function of the annealing temperature. (b) Concentration of the acceptor $\mathrm{A} 2\left(E_{V}+34 \mathrm{meV}\right)$ of the nonirradiated and the e-irradiated undoped $\mathrm{GaSb}$ samples as a function of the annealing temperature. (c) Fitted intensities of the two Ga vacancy-related defects $V_{\mathrm{Ga}, 280} \mathrm{ps}$ and $\mathrm{V}_{\mathrm{Ga}, 315 \mathrm{ps}}$ as a function of the annealing temperature.

a $\mathrm{V}_{\mathrm{Ga}}$-related defect. (The $\mathrm{V}_{\mathrm{Sb}}$ defect is expected to be positively charged and unable to trap positrons.)

Since a free three-component fit on the lifetime spectra is difficult, the spectra of the irradiated sample annealed at $T_{a} \leqslant 300{ }^{\circ} \mathrm{C}$ were fitted by fixing the two defect components at $280 \mathrm{ps}$ and $315 \mathrm{ps}$. The fitted intensities of the two defect components are shown in Fig. 1(c). From the figure, the annealing of the $315 \mathrm{ps}$ component is clearly seen at $300{ }^{\circ} \mathrm{C}$. It is also observed that the $280 \mathrm{ps}$ component intensity increases with annealing temperature, reaching a maximum at $T_{a}=300{ }^{\circ} \mathrm{C}$ before slightly decreasing.

One speculation is that the two different defect lifetimes may originate from the same $\mathrm{V}_{\mathrm{Ga}}$-related defect having different charge states and degrees of relaxation, a change in charge state occupancy being rendered by a change in the Fermi-level position incurred upon annealing. This proposal is ruled out since in the non-irradiated sample, the VGA, 315 ps defect anneals while the TDH measurements show no significant change in the Fermi level. Another possibility is that the two positron lifetimes originate from two $\mathrm{V}_{\mathrm{Ga}}$-related defects having different microstructures. However, the detailed structures of the two $\mathrm{V}_{\mathrm{Ga}}$-related defects are not known from the present data and this possibility would require further investigations.

PLS measurements $(20 \mathrm{~K}-300 \mathrm{~K})$ carried out on the $500{ }^{\circ} \mathrm{C} \mathrm{e}^{-}$-irradiated sample show an unchanging mean positron lifetime and a defect lifetime $(\sim 280 \mathrm{ps})$ and its intensity $(\sim 76 \%)$ which are temperature independent (shown in Fig. 2). This implies that the $\mathrm{V}_{\mathrm{Ga}, 280 \mathrm{ps}}$ defect center in the $500{ }^{\circ} \mathrm{C}$ annealed irradiated sample is neutral and its charge state occupancy does not change from $20 \mathrm{~K}$ to $300 \mathrm{~K}$. On the other hand, the TDH determined Fermi level $E_{F}-E_{v}$, shifted from $17 \mathrm{meV}$ to $79 \mathrm{meV}$ as the temperature changed from $20 \mathrm{~K}$ to $300 \mathrm{~K}$, implying that the $\mathrm{V}_{\mathrm{Ga}, 280 \mathrm{ps}}$ related defect center cannot be associated with the A2 acceptor $(\sim 34 \mathrm{meV})$. not accurately determined, reasonable values ranging from
Downloaded 08 Nov 2006 to 147.8.21.97. Redistribution subject to AIP license or copyright, see http://apl.aip.org/apl/copyright.jsp

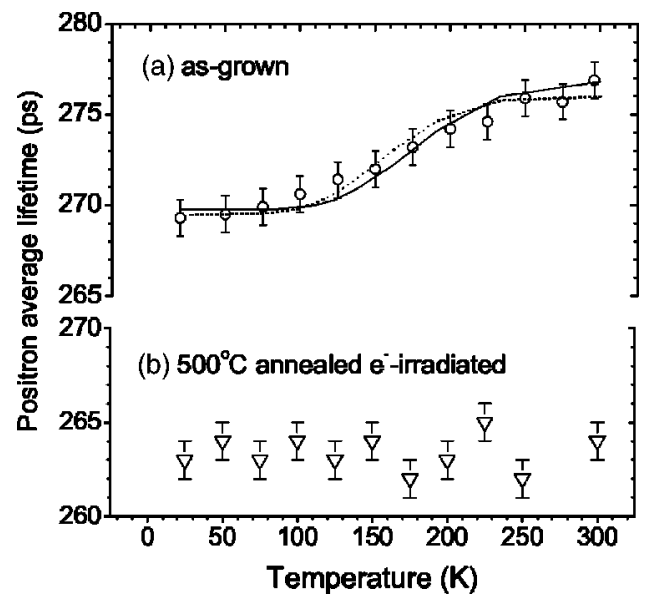

FIG. 2. (a) The positron average lifetime as a function of the measurement temperature for the as-grown undoped GaSb sample. The solid line is the model fit with no positron shallow trap. The dotted line is the modeled curve with the shallow trap's concentration and binding energy equal to 2 $\times 10^{17} \mathrm{~cm}^{-3}$ and $10 \mathrm{meV}$, and $E(0 /-)=70 \mathrm{meV}$ and $C\left[\mathrm{~V}_{\mathrm{Ga}, 315 \mathrm{ps}}\right]=8$ $\times 10^{16} \mathrm{~cm}^{-3}$. (b) The positron average lifetime as a function of the measurement temperature for the $500{ }^{\circ} \mathrm{C}$ annealed e-irradiated sample.

It is similarly possible to rule out any correlation between the $315 \mathrm{ps} \mathrm{V}_{\mathrm{Ga}}$-related defect and $\mathrm{A} 2$. For the nonirradiated sample, the measured hole concentration (and thus also $E_{F}-E_{V}$ ) remains constant at $\sim 2 \times 10^{17} \mathrm{~cm}^{-3}$ for the whole annealing temperature range. This implies that the charge state occupancy of the defect $\mathrm{V}_{\mathrm{Ga}}(315 \mathrm{ps})$ does not change with respect to annealing temperature. It thereby follows that the annealing of the 315 ps component in the nonirradiated sample at $300{ }^{\circ} \mathrm{C}$ must be due to the thermal annealing out of the defect. Moreover, since there is no significant change in the hole or A2 concentrations accompanying the $300{ }^{\circ} \mathrm{C}$ annealing, the $\mathrm{V}_{\mathrm{Ga}}$-related (315 ps) defect cannot be an important acceptor in determining the electrical property of the material.

Temperature dependent PLS measurements carried out on the as-grown undoped $\mathrm{GaSb}$ samples from $20 \mathrm{~K}$ to $300 \mathrm{~K}$ (corresponding to $E_{F}-E_{V}$ $=20 \mathrm{meV}-72 \mathrm{meV}$ ) show the average lifetime increases with temperature (Fig. 2). This behavior may be due to the ionization of the $\mathrm{V}_{\mathrm{Ga}}$-related ( $315 \mathrm{ps}$ ) defect and/or the existence of a positron shallow trap. A model consisting of a shallow trap and the $\mathrm{V}_{\mathrm{Ga}}$-related (315 ps) were constructed to fit for the positron average lifetime data. The charge state occupancy for the $\mathrm{V}_{\mathrm{Ga}}$-related defect is obtained from: $\left[\mathrm{V}_{\mathrm{Ga}, 315 \mathrm{ps}}\right] /\left[\mathrm{V}_{\mathrm{Ga}, 315 \mathrm{ps}}^{Q+1}\right]=\left(g_{Q} / g_{Q+1}\right) \exp \left[-\left(E_{i}-E_{F}\right) /(k T)\right]$, where $E_{i}$ is the corresponding ionization energy, keeping the total concentration of defect $\mathrm{V}_{\mathrm{Ga}, 315 \mathrm{ps}}$ constant. The positron trapping rate into $\mathrm{V}_{\mathrm{Ga}, 315 \mathrm{ps}}$ is then given by: $\kappa_{Q}$ $=\mu_{Q}\left[\mathrm{~V}_{\mathrm{Ga}, 315 \mathrm{ps}}^{Q}\right]{ }^{5,6}$ The specific trapping coefficient of $\mathrm{V}_{\mathrm{Ga}, 315 \mathrm{ps}}^{Q}\left(\right.$ i.e., $\left.\mu_{Q}\right)$ is taken to be constant for the neutral vacancy and follows $\mu \sim T^{-0.5}$ law for the negatively charged vacancy. ${ }^{5,6}$ The positron dynamics were described by standard rate equations for trapping into the $\mathrm{V}_{\mathrm{Ga}, 315 \mathrm{ps}}$ defect and spectra then give the average positron lifetime $\tau_{\mathrm{ave}}=\sum_{i=1}^{4} I_{i} \tau_{i}$. Since, as demonstrated, the most abundant acceptor A2 $\left[C(\mathrm{~A} 2) \sim 2 \times 10^{17} \mathrm{~cm}^{-3}\right]$ is not related to the two $\mathrm{V}_{\mathrm{Ga}}$-related defects, it is itself, in its ionized state, a possible candidate for a positron shallow trap. Although its binding energy is the shallow trap. ${ }^{5,6,10}$ The resulting four component lifetime 
$10 \mathrm{meV}$ to $100 \mathrm{meV}$ have been employed in fitting. The details of fitting and the values of other parameters can be found in Ref. 10. Good fittings to the data could be obtained with the shallow trap concentration of $2 \times 10^{17} \mathrm{~cm}^{-3}$, and the $\mathrm{V}_{\mathrm{Ga}, 315 \mathrm{ps}}$ parameters lying in the range of $E(0 /-)$ $=70-85 \mathrm{meV}$ and $\left[\mathrm{V}_{\mathrm{Ga}, 315 \mathrm{ps}}\right]=5-8 \times 10^{16} \mathrm{~cm}^{-3}$. The shallow trap concentration is in good agreement with the $C(\mathrm{~A} 2)$. It is noted that the $\mathrm{V}_{\mathrm{Ga}, 315 \mathrm{ps}}$ 's ionization energy and concentration coincide well with those of the A3 acceptor $\left(\sim 89 \mathrm{meV}\right.$ and $\left.6.5 \times 10^{16} \mathrm{~cm}^{-3}\right)$. This concurs with the $300{ }^{\circ} \mathrm{C}$ annealing temperature of $\mathrm{V}_{\mathrm{Ga}, 315} \mathrm{ps}$, at which the $\mathrm{A} 3$ concentration also dramatically decreases to 1.2 $\times 10^{16} \mathrm{~cm}^{-3}$. The A3 acceptor is thus believed to be related to the $(0 /-)$ transition of $\mathrm{V}_{\mathrm{Ga}, 315 \mathrm{ps}}$.

Having concluded that the two identified $\mathrm{V}_{\mathrm{Ga}}$-related defects are not associated with the A2 acceptor, it is interesting to inquire as to the identity of the A2 defect. From firstprinciple calculations, Hakala et al. ${ }^{3}$ have shown that the $\mathrm{Ga}_{\mathrm{Sb}}$ acceptor has an ionization level at $E_{V}+0.04 \mathrm{eV}$, which is close to the presently observed $34 \mathrm{meV}$ ionization energy of the A2 acceptor. In the same study, it was pointed out the formation energy of the $\mathrm{Ga}_{\mathrm{Sb}}$ antisite was found to be the lowest among the other native defects and thus it should be an abundant defect in the GaSb material. Based on the experimental Hall data and thermodynamic considerations, Shaw ${ }^{4}$ also argued that the $\mathrm{Ga}_{\mathrm{Sb}}$ should be the residual acceptor of GaSb. Our present findings that the acceptor A2, with ionization energy of $\sim 34 \mathrm{meV}$, is the most important acceptor responsible for the $p$-type conduction is thus consistent with the picture of $\mathrm{A} 2$ being the $\mathrm{Ga}_{\mathrm{Sb}}$ antisite.
In conclusion, we have investigated the acceptors in undoped LEC-grown GaSb. The $34 \mathrm{meV}$ acceptor was found to be the important one responsible for the $p$-type conduction in both the nonirradiated and the $\mathrm{e}^{-}$-irradiated undoped materials annealed at temperatures up to $500{ }^{\circ} \mathrm{C}$. This acceptor is not related to any $\mathrm{V}_{\mathrm{Ga}}$-related defect detected and is most likely the $\mathrm{Ga}_{\mathrm{Sb}}$ antisite.

This work was financially supported by the RGC, HKSAR, P. R. China (Project Nos. 7134/99P and 7107/02P), and the CRCG, HKU.

${ }^{1}$ A. G. Milnes and A. Y. Polyakov, Solid-State Electron. 36, 803 (1993).

${ }^{2}$ P. S. Dutta and H. L. Bhat, J. Appl. Phys. 81, 5821 (1997).

${ }^{3}$ M. Hakala, M. J. Puska, and R. M. Nieminen, J. Appl. Phys. 91, 4988 (2002).

${ }^{4}$ D. Shaw, Semicond. Sci. Technol. 18, 627 (2003).

${ }^{5}$ R. Krause-Rehberg and H. S. Leipner, Positron Annihilation in Semiconductors, Defect Studies, Springer Series in Solid-State Sciences, Vol 127 (Springer, Berlin, 1999).

${ }^{6}$ M. J. Puska and R. M. Nieminen, Rev. Mod. Phys. 66, 841 (1994).

${ }^{7}$ J. Mahony, G. Tessaro, P. Mascher, H. Siethoef, and H. G. Brion, Mater. Sci. Forum 196, 1449 (1995).

${ }^{8}$ S. Dannefaer, W. Puff, and D. Kerr, Phys. Rev. B 55, 2182 (1997).

${ }^{9}$ M. J. Puska, S. Mäkinen, M. Manninen, and R. M. Nieminen, Phys. Rev. B 39, 7666 (1989).

${ }^{10}$ C. C. Ling, S. Fung, and C. D. Beling, Phys. Rev. B 64, 075201 (2001).

${ }^{11}$ C. C. Ling, W. K. Mui, C. H. Lam, C. D. Beling, S. Fung, M. K. Lui, K. W. Cheah, K. F. Li, Y. W. Zhao, and M. Gong, Appl. Phys. Lett. 80, 3934 (2002).

${ }^{12}$ P. Kirkgaard, M. Eldrup, O. E. Morgenson, and N. J. Peterson, Comput. Sci. Commun. 23, 307 (1981).

${ }^{13}$ The detailed results and analysis of this study will be included in another article presently under preparation. 